\title{
PURCHASING HABITS AND MARKET POTENTIALITIES OF THE OLDER CONSUMER
}

\author{
ROBERT E. DODGE*
}

\section{INTRODUCTION}

Market structures have always been dynamic, changing in emphasis as one segment or another enlarged or decreased. In the twentieth century an especially rapid change in the basic age distribution has taken place. Within the past few years a change in age distribution has resulted from the rapid growth of that segment of the population which is 65 years of age and older. During the past sixty years, the number of persons in this age group has increased more than fifty per cent. In I900, only 4.I per cent of the entire population of the United States were sixty-five years of age or older. ${ }^{1}$ In $1960,9.2$ per cent of the population were in this age group. 2

When the population within this age stratum was small, marketers naturally were unconcerned. With relative scarcity of products, especially during and after war periods, there was little reason for marketers to pay attention to the characteristics of individual markets. 'Today, marketers face a buyers' market where attention to the needs and desires of each market segment may be meaningful. Now that the population 65 years of age and older has increased with such rapidity, and to such proportions, it is attracting attention, but because this is a new market and because of the lack of information about it, marketers have tended to do nothing.

In order to obtain information about the marketing characteristics of this enlarged older population, a sample of the population of Portland, Oregon, was selected and interviews were conducted to obtain information revealing certain attitudes and buying patterns of this population. This article summarizes the major findings of that study. ${ }^{3}$

\section{I}

\section{The Changing Social Role of Order Persons}

Economic and marketing characteristics reflect the demands of society. While economies were essentially agricultural, the role of the older person was an enviable

* A.B. I934, A.M. I95I, University of Oregon; Ph.D. I956, Graduate School of Business Administration, New York University. Professor, Portland State College (Oregon). Contributor to professional and business publications.

${ }^{1}$ U.S. Bureau of the Census, Dep't of Commerce, Census of Population: 1950, Vol. 2, Characteristics of the Population, Part r, p. I-93, table 39 (I953).

${ }^{2}$ U.S. Bureau of the Census, Dep't of Commerce, Census of Population: ig6o, United States Summary, General Population Characteristics, pe (I) I B.U.S., p. I-I48, table 46 (I96r).

${ }^{3}$ For expansion of this information, see Robert E. Dodge, AN Analysis of Centain Characteristics of the Market of Persons Sixtx-Five Years of Age and Over Together with a Consideration of Merchants' Atritudes Toward that Market in Portland, Oregon (unpublished dissertation in New York University Graduate School of Business Administration Library 1956). 
one. Old people were often leaders of the tribe or social group and their advice, opinion, and leadership-largely due to maturity-placed them in a favored position. Older persons, in their wisdom, were respected, and their place in society was one of considerable importance. In some countries-for example, China-older persons were venerated. As economies changed from agriculture to industry and as the population grew rapidly in the younger ages, older persons found themselves less needed and therefore less wanted by society. Old age became a symbol of uselessness, and old persons became a social burden.

In America during industrialization, the attitude of the whole population reflected the needs of our early economic and social development. In fact, it was necessary in the development of the country to emphasize youth and strong physical vigor. The frontiers of the land presented hardships and difficulties which required youthful energy to meet its hazards. The ideal American at that time was young, healthy, fearless, and strong. Something of that ideal has carried over into our modern life and still may be the fetish worshipped by the population. With the national ideal based on the assumption that youth was the most desirable state for man, older persons were considered a necessary burden on society, and their function was to wait quietly and patiently until death occurred. As our population in this age group was very small, the problem actually seemed a very minor one, and the group apparently accepted the role they thought society had established for them. But within the brief space of fifty years, a rapidly increasing population of older citizens has caused a change in the attitude of the total population. No longer do senior citizens feel that their potential contribution to society is ended. As they observe numerous older persons in fine health and enjoying activity, they see emerging a changing attitude which may allow them to live as active members of our society. This new role for senior citizens is now in the process of evolving. Older persons have greater freedom of expression in every direction today, although this development is perhaps slower than the numerical increase within that segment of the population.

Business leaders have an opportunity to show older persons the possibilities now opening to them for a fuller life. In fact, marketers can wield a great influence in hastening the acceptance of a new philosophy which can aid senior citizens in better adjustment to our present society. As the numbers in this age group have increased rapidly, marketing problems are becoming evident, and still relatively little is known concerning the true nature of this changing market.

An awareness of some of the changes which profoundly influence the status of the older population will make possible a more accurate evaluation of the marketing potential of this group today. The contribution of medical science has been an important factor in the formation, continuation, and growth of this age stratum. Breakthroughs to solutions of some of the critical geriatric problems could mean an even greater growth in the older population than has been projected. The advances that have been made in the treatment of the ill and the development and use 
of drugs have increased the feeling of security for the older group. Many older persons now have health and accident insurance to protect them during illness. For centuries fear of prolonged illness was a motivating factor in asset saving. It was considered socially important, if not personally necessary, to save for one's old age and to provide enough funds for prolonged illness and final death services. With insurance, pensions, and governmental plans, the senior citizen is less concerned with illness and death costs and, therefore, may not feel the strong compulsion to save for these purposes.

The government has taken an active interest in the several problems of the aged by granting special concessions to older persons. There is no reason to believe the practice will be diminished; in fact, assistance will probably increase in the future.

As the social and economic status improves, as the segment of the population within this age group continues to increase, and its members become more vocal in their demands, society will give increased attention to their needs and wants.

\section{II}

\section{An Emerging Market}

Groups often "play the role" which they think society expects of them. Until recently, older people were expected to live quietly, clothe themselves conservatively, and to make way for the younger, more necessary, producers of our economy and society. The younger society, busy with the problems of youth, paid little attention to the desires of the old. To illustrate, most garments were and still are made for young people. Old people were expected to dress in dull, conservative patterns; and little attention was given by designers to the problems of the aging figure. The colors and styles available were limited to a few designs in drab colors, such as black, gray, blue, and white. Little thought was directed to the need of older women for youthful looking colors, for longer sleeves to cover unattractive arms, and for flattering rather than flattening styles.

All persons sixty-five years of age and older were boin before rgoo when our economy was still primarily agricultural. The impressions of their youth are strong, and the attitudes of their parents and grandparents carry over into the attitudes of the present older population segment. But a change in the social role of older persons is becoming apparent. With nearly ten per cent of the population in the older age group, they are now numerous enough to demand attention. With more older persons being well and active, they see the prospect of a considerable number of years of life ahead. With medical advances, attitudes of possible usefulness to society, possession of insurance protection, and governmental interests and provisions, they feel more secure. Many see themselves as freed from work and the cares of a young household. More attention is being given to them; they feel more important, which may positively affect their morale. This may result in older persons re-analyzing their positions and thereafter demanding additional attention: 
This can lead to an expanding market as older persons seek their new "role" in modern society.

\section{III}

\section{Assets of Older Persons}

The existence of a large population segment is of paramount concern to marketers, but ability to buy is an integral part of the marketing process. Without disposable income there can be no market, but disposable income is a relative concept. Comparison must be made between the "cost of living" and the income or savings of the population in order to determine what older persons may spend for other than basic living needs.

Size of income alone has less significance than the family status or financial responsibilities of the older person which condition his spending patterns. The Joint Committee on Problems of the Aging of the New York State Legislature, in its 1956 publication, New Channels for the Golden Years, estimated the total income of older persons to have been $\$ 20$ billion in 1954 . It forecast a rise to $\$ 32$ billion by 1965 . But these estimates have little meaning until broken down into specifics. Although some data are available concerning previous spending patterns of the population, it should not be assumed that past actions predetermine future behavior. (Interviews with older persons reveal they often accept what is available in the market because they are unable to get what they really want).

It is true that older people do not spend as much money as younger persons. A recent study revealed that families whose age of household head was 65 years and over spent $\$ 2,405$ per year for all goods and services compared with $\$ 4$,IIo for all households. The study arrived at a different finding, however, when per capita statistics were examined. The older person spent \$1,319 per member compared with $\$ 1,245$ per member for all households. ${ }^{4}$ When considered, therefore, on an individual basis, spending by the older person appears to be more significant.

Estimates of financial characteristics of the older population are subject to considerable bias. Some of the agencies which have analyzed financial aspects of population problems may have been influenced by a desire to show "need" on the part of the older population. A further difficulty is the necessary estimation used in arriving at income in kind, home ownership, contributions from relatives, and similar resources which are not readily measurable. ${ }^{5}$ Older persons may be sensitive and fearful and, therefore, reluctant to divulge all of their sources of income or accumulated assets. The amount of interest, dividends, annuities, and rents may be revealed incompletely, if at all. Epstein suggests the difficulty in obtaining accurate statistics: ${ }^{\mathbf{B}}$

\footnotetext{
- Alfred Politz Research, Inc., Life Study of Consumer Expenditures-A Background for Marketing Decisions 23 (Time, Inc., 1957).

${ }^{8}$ John J. Carson \& John W. McConnell, Economic Needs of Older People 39 (1956).

'Epstein, Economic Resources of Persons Aged 65 and Over, Soc. Sec. Bull., June I955, pp. 3, Io.
} 
[It] ... may be estimated that perhaps 250,000 of the 700,000 men and 600,000 women of the 2.I million women with no income from employment or a public incomemaintenance program at the end of $195 \mathrm{I}$ had investments that yielded some cash returns. If, as seems probable, there was little change between December I95I and December r 954 in the proportion of aged persons with income from assets, perhaps half of the men and one-third of the women without income from employment or a public incomemaintenance program in December 1954 had some money income from assets.

For marketing purposes it is important to realize that, although these sources of income are not large when they are added to other sources, the total may have a significant impact upon purchasing patterns. Although assets and incomes of older persons tend to be considerably less than for younger households, demands upon them are greatly decreased, ${ }^{7}$ primarily because their total indebtedness is much less as their homes have been paid for during their younger, higher-earning years. The tendency to change living habits as little as possible results in spending more (dissaving) in proportion to their income than do persons in their early and middle adult years.

Another important consideration for marketers is to recognize the fluid nature of the disposable funds of older persons. They may have less income and assets but they also have fewer ties to family responsibilities. With their homes paid for, their major housing concern is for property taxes and repairs. Fear of extended illness has been lessened because of geriatric advances. Increased evidence of governmental concern and assistance makes saving less attractive. With their children through school, with jobs and households of their own, older persons are less obligated by family responsibilities. Being essentially free from obligation, they may spend their income and assets as they wish. They may spend for whatever happens to meet their desires. Here is a potential market, therefore, for those marketers who wish to appeal to it. It is a new market, almost unrecognized, which must be developed with care as it depends upon the changing role of older persons in our society and the realization by older persons that they are more free than their predecessors in the past century.

\section{IV}

\section{Differentiation of the Older Consumer}

Although recognition has been given to the existence of a market composed of older persons, the market is not an easy one to identify. ${ }^{8}$ In fact, it would be difficult to prove that this is a clearly identifiable single market. Rather, as is frequently the case, it is a clustering of markets with identifying elements related to age and its problems but which may differ widely because of the health, activity, and age of the

\footnotetext{
'Sidney Goldsten, Consumption Patterns of the Aged-A Study of Consumer Expenditures 37 (1960).

"U.S. Federal Security Agency, Comm. on Aging and Geriatrics, Fact Book on Aging 18 (1952).

Murdoch, After the Gold Watch, Federal Reserve Bank of Philadelphia Bus. Rev., April 196r, p. Io.
} 
population. The problem is further compounded by the differences in chronological and physical or mental age. Some people in their nineties are as active and well as those forty years younger. A further difficulty is the reluctance to be categorized as an "older person." Considering the premium which our society has put on youth, the older person may not wish to be identified as "old." This is especially true of those whose age is within the decade after 65. In interviews with older persons, a difference in response was observed in that as people reach the seventies and beyond they may often be proud of that fact and, therefore, more cooperative in giving information than the younger "oldsters" who may be more sensitive to the transition into older age. A clearer differentiation may be observed in accordance with the attained age of the older person. The older the person, the more identifiable his wants tend to be. Appeals to the older customer (except for the very old) must therefore be very tactful, recognizing the need but not emphasizing the differentiation.

So far little evidence has been discovered that manufacturers and retailers have been aware of possibilities in this area, and some are even somewhat antagonistic to the idea of serving an older market. Other merchants are interested but have no idea what the market is nor how to appeal to it. ${ }^{10}$

$\mathrm{V}$

\section{SpENDING Habits}

Two major studies which show how persons 65 years and older spend their money have been made. In 1950, the Bureau of Labor Statistics and the Wharton School of the University of Pennsylvania made a detailed comprehensive analysis of the purchases of older persons. In 1956, Life magazine conducted a study of the expenditures of all age levels, including the households headed by persons aged 65 years of age and older. The latter study showed that a proportionately greater share of the older household's consumption dollar was spent on food. Because food is a necessity and older persons have less money, a larger proportion of their income will be spent on food. Dietary factors may also create a differentiating quality. Older persons may require different types of foods, such as those with high protein and mineral content. Some older persons cannot chew easily and, therefore, must eat chopped or puréed food. They may select baby food which provides them a small quantity as well as easily assimilated food. Older persons may hesitate to buy "regular" size cans of foods because they tire of the same food before they can consume an entire large can. The small cans of baby food provide variety and ample food for a single serving. ${ }^{11}$ Manufacturers could easily use an appealing label with no change in content or size of can for the older consumer.

Some of the foods which older persons require are specialty goods which may be relatively expensive and thereby increase food expenditures. Older persons

${ }^{10}$ DodGe, op. cit. supra note 3, at 196.

"Id. at 134-36. 
have different spending patterns according to their income level. As Murdoch stated, older families with high incomes ( $\$ 7,500$ to $\$$ ro,000 a year) spend only seventy per cent as much for food as comparable younger families. ${ }^{12}$. The Bureau of Labor Statistics and Wharton School study revealed that differences in age (until 75 years is attained) have relatively little consequence for food consumption patterns. They found a minimum of variation with changing age level subject mainly to income differences. With adequate incomes, household food expenditures varied little. ${ }^{13}$

Medical care claims a larger proportion of the older consumer's income. The Life study reported that older households allocate six per cent of their income to medical and personal care, as compared to five per cent for younger families. The Bureau of Labor Statistics and the Wharton School found that older households spend thirteen to thirty-seven per cent more for medical care than younger families. The discrepancy between the two studies may be due to the inclusion of personal care in the Life study and distortion by differences in family size.

\section{VI}

\section{HousING NEEDS}

Housing for older persons has attracted attention because of the need for adequate housing facilities. Some differentiating qualities may be observed, such as the need for small, compact, and convenient homes. The older person often becomes lonely and may wish to live in an apartment in order to be near others. Older persons often sell their homes, which may be too large with lawns and extensive upkeep, and move into city apartments. New apartment houses are now being built in most larger cities for the older persons. The older person may wish to live close enough to the center of a city in order to have all services available within walking distance or at least close enough for easy transportation.

House construction specifically for the older consumer is still definitely in the experimental stage. Ease of access, safety, convenience, and compactness must be provided. There is some question whether the older consumers have themselves given enough careful consideration to the exact nature of their requirements. As more attention is given to the problems of older persons, housing which is better planned for their needs will evolve. Although older persons change their locations less frequently than do others, many are unaware that homes which suit their requirements better are obtainable. Precipitous purchasing when older persons move may deny them the type of housing best suited to their requirements.

Level rather than split-level houses are needed, with ample storage space for accumulated materials. The least possible stairs should be provided, and these should have low risers, wide steps, and sturdy hand rails. Space for hobbies or projects should be provided. The house must be well sealed to prevent drafts, and insulated to hold the heat constant even at the high temperatures sometimes needed

\footnotetext{
${ }^{28}$ Murdoch, supra note 9, at Ir.

${ }^{23}$ Goldstein, op. cit. supra note 7, at 69 .
} 
by older persons. Special conveniences should be provided, such as wide door. ways, non-slip flooring throughout, and ease in maintenance. There should be places to sit throughout the house. Electrical outlets should be high enough so that people do not have to stoop. Lighting should be bright enough to illuminate the rooms adequately, but not enough to cause glare. Room colors should be cheerful, not drab, and yet not so brilliant as to emphasize the physical changes aging may cause. As many "built-ins" should be supplied as possible commensurate with the conservative price range of the house.

Older people devote a slightly greater proportion of their income to housing and home maintenance than other age levels. They spend less on the larger household products, such as washers, ironers, refrigerators, and ranges.

\section{VII}

\section{Personal Services}

Expenditure for personal care is a relatively small category for all income groups, and the older group spends less for this purpose than do other age levels. The nature of the services involved conditions spending patterns. Older people may prefer to perform their services themselves or even to go without them. There is a distinct difference between the expenditures of older persons for personal services in accordance with their income level. The higher the income, the greater is the amount of expenditure for personal services. As incomes for older persons increase, the demand for personal services will expand. The need for these services is perhaps actually greater for the older consumer than for younger people. Older people may need toiletry services which may reduce signs of aging. A physical impairment may require some older persons to seek personal service. Education in the availability of many "beauty aids" could bring added awareness of the services obtainable by the older population. ${ }^{14}$

The market for recreation for the older age group has received little recognition, with the single exception of travel. Travel frequently appeals to the older person, and some transportation companies have provided special arrangements at less than normal rates to appeal to older persons. Retirement at the age of 65 is typical for many types of work, so that persons have time to engage in any type of activities they desire when they reach this age. The expenditures for recreation drop steeply, however, for persons in the older age group, the amount spent correlating inversely with the advance of age. ${ }^{15}$ Goldstein cites income as being mainly responsible for the variation in purchases of recreation facilities by older persons. For example, data from a Consumer Expenditure Survey revealed that radio ownership varied from sixty-three per cent of those with incomes less than $\$ r, 000$ to a high of seventy-one per cent for those with incomes greater than \$10,000 a year. Ownership of television sets showed a greater variation: three per cent for the $\$ 1,000$ and under group compared with forty-five per cent for those with incomes greater than 
$\$ 10,000 .^{16}$ With increasing incomes, older persons will be financially able to spend more on recreation.

The differences in behavior patterns before and after retirement make the transition a difficult one. Older persons tend to continue to live with as little change as possible in their life patterns, dependent upon assets and income. However, they find freedom from work results in free time which often becomes frustrating and tiresome. Recreation may provide the opportunities for activity heretofore impossible. But for the older person the transition from work to "play" may be awkward and associated with feelings of guilt or inadequacy. In other words, if the market for recreation is to be served adequately, the older person's role in life must be clarified for him, and he must be educated to the importance of recreation in his life. Proper adjustment to the life of retirement may be encouraged by the use of recreational facilities by the older population. This market must be developed by tactful appeals containing educational messages to the older group encouraging them to lead fuller lives in the enjoyment of the products and services of our modern economy.

\section{VIII}

\section{The Portland Studx}

A sample of the older population of the city of Portland, Oregon, was interviewed to reveal shopping patterns. ${ }^{17}$ The city's apparel stores were used as a basis for the study. The stores were classified according to physical size and volume of sales. The largest store in the city, a popular-priced department store, was reported to be the preference over all other stores. Other preferences expressed by the older population indicated that a large proportion preferred the large department store over medium-sized or specialty shops. The first preference reported was good assortments. The second most important factor reported was price. The third was quality; fourth, availability of goods; and fifth, convenience. Habit was another important factor as many older persons reported they liked to shop in familiar places. They also expressed a preference for shopping in the central shopping districts, particularly in the "downtown" retailing areas.

\section{A. The Appeal of Special Sales}

The older population was interrogated concerning reaction to special sales. In apparel, particularly, sales were found to have little appeal. Two-thirds of the persons interviewed reported they did not wait for sales, as compared with one fifth who said they did wait for them. A typical complaint was that the quality of the merchandise offered on sale was not good, and that items of particular interest often were not included in the sale. Fifteen per cent stated they seldom waited for sales. Eighty per cent expressed limited or no interest in sales.

${ }^{20}$ Id. at 184 .

${ }^{17}$ Dodge, op. cit. supra note 3 , at $117-32$. 


\section{B. Apparel Preferences}

The women interviewed reported dresses to be the apparel item most frequently purchased. Only twenty-four women's suits were purchased in a full-year period by the entire female sample of the population, indicating that this type of apparel has very limited appeal to the older person. Six of these suits were in the \$roo-andover price range. The most frequently quoted price paid for suits was between $\$ 25$ and $\$ 49$. The modal average price paid for house dresses was within the $\$ 3.95$ to $\$ 5.95$ price range, with the second most popular price range from $\$ 6.00$ to $\$ 9.95$. About fifty per cent of the women interviewed reported the purchase of a coat during the preceding twelve months, for which they customarily paid between $\$ 25$ and $\$ 49$. The persons interviewed purchased slightly less than one "better" dress each year, paying between $\$ 25$ and $\$ 49$. Several mentioned receiving better dresses as gifts from relatives, indicating the existence of an indirect demand for these products. They also reported using worn better dresses for house dresses.

The older men reported purchases by over half the group of "ready to wear" suits, paying from $\$ 45$ to $\$ 99.95$. Less than three per cent stated that they paid more than \$roo for suits. They liked vests and two trousers with their suits. Few older persons purchased jackets, although over one half of the persons interviewed reported buying separate trousers at prices between $\$ 3$ and $\$ 14.95$.

Older men tend to be conservative in dress and usually purchase suits rather than casual clothing or jackets and slacks. There were indications in their responses that a trend toward less formality in dress may be forming. Inquiry among employees of apparel stores revealed that although the older men still preferred suits, an increasing number of jacket and trouser combinations were sold to older customers. Merchandise buyers believed that the older group really preferred more informal clothing, and that the trend would be in this direction. It was discovered that the purchase of suits by men in this age group was not a frequent pattern, but that they were willing to pay a relatively high price to get exactly what they wanted. Older men frequently were given either used or new clothing by relatives and friends. Shirts were frequently received by older men as gifts, and therefore relatively few were purchased directly by them.

Investigation of material preferences revealed a strong preference for wool in coats and suits. Some persons stated a preference for wool in better dresses and even house dresses, although there was a strong preference for cotton in house dresses. None stated a preference for cotton coats or suits.

Older persons showed some negative responses to synthetic materials. A common complaint was that synthetics frequently cause allergic skin reactions. Other objections to synthetics were that they are too hot in summer and too cold in winter, and that they cling to the body, emphasizing some of the physical evidences of age. Although there was a negative attitude toward synthetics, it was discovered that many older persons, having used cotton and wool all of their lives, are really 
unfamiliar with synthetic fibers and therefore, because of lack of knowledge, mistrust them.

\section{Apparel Style and Fit}

The persons interviewed were of the opinion that they experienced some difficulty in securing the proper style and fit in clothing. A major problem was finding conservative styles. It was stated that garments are not made for older persons, who said that they desired clothing more simple in design, of cheerful but not loud colors, and of warm material. Consideration in minimizing the physical evidence of aging was suggested. In shopping for clothing, older persons said that they were usually shown one or two dresses in extremely conservative styles in either black, gray, or blue, with little style variations. They indicated a desire for better fitting, better styling, more colors, and greater assortments. They stated that assortments of clothing for older persons are so limited that almost no choices were available.

\section{Attitudes Toward Returning Merchandise and Other Customer Services}

Questions were asked to ascertain the attitude of sales persons toward the older population. It was discovered that older people do not think that sales people are attentive, courteous, or helpful. Some older persons thought that sales people deliberately preferred not to sell to the older population.

A large percentage of those interviewed expressed strong attitudes toward returning merchandise once purchased. More thian sixty per cent stated that they 'did not return merchandise at all, showing a definite dislike for doing so. Only 2.I per cent said that they returned merchandise wherever they desired to do so. Findings from the interviews revealed an emotional overtone when responses to this question were obtained. A typical comment was "Oh, I don't like to return merchandise." An example which reflects the attitudes of older persons was cited by one man who had purchased a suit of clothes which did not fit him properly. Rather than return it or even consider alterations, he left the suit in a closet and has never worn it.

Inquiry was made to determine the extent of mail order purchasing. Only two per cent used mail orders extensively, although twenty per cent said that they purchased by mail order occasionally. Little enthusiasm for this type of purchase was expressed. A frequent comment volunteered was, "I like to see what I am buying." When interrogated concerning purchasing by telephone, fourteen per cent stated that they used this method frequently, and an equal percentage said they used this method occasionally, but a strong preference for examining the merchandise in person was expressed.

Possession of charge accounts was reported by close to fifty per cent of the population. The persons interviewed usually had charge accounts with the major city department stores rather than with specialty shops. Fifty-two per cent of those 
who had charge accounts reported frequent use of them. . Typical responses showed a definite preference to pay cash for purchases.

\section{E. Additional Store Services Desired}

It was asked what additional services stores should provide. Some expressed a desire for more places within the store for people to sit and rest, for larger stocks or assortments of merchandise appropriate to the needs of older customers, better delivery services, wider aisles, better and clearer store directories and signs, and better lighting. Many older persons stated they did not like to shop in crowded stores where it was difficult to move around.

Older people reported that they did not usually attend classes, demonstrations, fashion shows, or special promotions. Attendance at store-sponsored special events is not characteristic behavior for the older population.

Window shopping is particularly appealing to older persons. Over fifty-five per cent stated they liked to window shop. Those who window shopped expressed a definite interest in observing the displays of merchandise. A typical comment was "window shopping is my favorite recreation." It should be noted that both males and females expressed interest in this. They also showed preference for newspapers as a preferred medium for noting the advertising messages of distributors and producers. ${ }^{18}$ Over sixty-three per cent of those interviewed did not believe that they utilized radio or television advertising when contemplating purchases.

Inquiry was conducted to determine the shopping pattern for specific needs. Sixty-one per cent reported that they did not shop or "browse" unless they desired some particular product or service, but twenty-four per cent reported shopping whether or not they desired a specific product or service.

Over fifty per cent stated they preferred to shop alone. During the interviews, the comment was frequently volunteered that the influence of other people, including household members, was not helpful in shopping. The older persons desire to take their time and to make their decisions by themselves without suggestions from others.

\section{F. Importance of Physical Condition and Health}

In order to determine the importance of diet restrictions and thereby the implications for food purchasing, older persons were interrogated concerning the extent of diet restrictions. Over eighty-three per cent stated that they were not on a special diet, as against approximately sixteen per cent who stated they were. The evidence obtained gave support to the assumption that the great majority of older persons are not on a regulated diet. Therefore, restrictions on diet may be considered to have little effect upon food purchases.

An hypothesis was formed that if older persons were in good health or believed

${ }^{18}$ This could well have implications for merchants in that window shopping and newspaper advertising appear to be especially attractive to the older population. 
themselves to be healthy, their attitudes would have implications concerning shopping patterns. Over sixty-four per cent of those interviewed stated that they were in good health. A very small percentage considered themselves in poor health. It thus appears that a large majority of the older population consider themselves to be in good health. The significance of this finding is related to the nature of the purchases which older persons will make, and may also have an impact upon attitudes reflecting marketing patterns. Persons in good health may tend to be more optimistic and may place less emphasis on age and its problems. This may tend to make their purchasing habits follow a "normal" pattern.

A control question relating to the frequency of being under the care of a physician confirmed the previous finding. Over seventy-two per cent stated that they were not under a physician's care. Further investigation ascertained the extent of physical impairment of the group. If it had been determined that a significant proportion of the older population were physically disabled, an impact upon shopping patterns would have been inevitable. Less than ten per cent were found to be physically disabled. With this finding, the factor of being unable to engage in shopping was believed to be virtually eliminated.

\section{G. Transportation and Mobility}

Fifty-seven per cent of the older persons interviewed did not own automobiles. Therefore, a large segment of the population must depend upon public transportation, relatives, friends, or perhaps, walking to shop. The most frequent complaint about public transportation was that the routes of the vehicles did not approach closely enough to the homes of the older persons. Another factor was the lack of frequent service from the public carriers. A large proportion of the older population does use public transportation, especially busses for shopping excursions beyond walking distance.

Among the less than fifty per cent who own automobiles, investigation was made of the make of automobiles preferred. It was found that the so-called "popular" priced automobiles are the choice of most of the automobile-owning members of the older population.

Investigation was also made of the mobility of the population outside of the immediate area, to indicate the stability of the older population within the urban area and to provide information which might be important for the travel industry and for transportation facilities. Interviews revealed that a large portion of the older population does not like to leave home except for occasional trips. Travel is directly correlated with income. The wealthier older persons may "go South" during the winter months to escape the winter storms and cold. California and Arizona were cited as the place where many older persons prefer to spend the winter. There was evidence that often a trip or trips immediately follow retirement, after which the voyager may choose to "settle down" in his home. A more frequent length of visit away from home was reported to be two weeks. A study of the type of transpor- 
tation used by the travelers revealed that the majority used their own automobiles. The train was the second method of travel, followed by bus, airplane, and ship in order of preference.

Responses showed that people were less conscious of old age now than they were formerly. Typical comments were that numerical age has less importance today, and that as long as older people keep active and interested, chronological age does not need to have any meaning. Over fifty-seven per cent of those interviewed thought that chronological age was less significant now than it was considered to be during the earlier part of the twentieth century. The observation was made by the interviewers that if the persons interviewed were in good health and their voices strong and vigorous, they tended to underrate the impact of chronological age. Those who were obviously ill or infirm were more conscious of age. Inquiry about awareness of change in buying patterns after 65 years of age revealed that fifty-four per cent of those interviewed were conscious of some changes: buying somewhat less, wanting less, or needing fewer products and services. Forty-two per cent were not conscious of any change in their buying habits after reaching the age of 65 years.

\section{Summary}

Each decade of the twentieth century has shown a numerical increase in number of persons 65 years of age and older. The percentage of older persons within the population has increased consistently. There is little evidence that this trend toward a constant increase will be substantially altered during this century. Therefore, barring a catastrophe, an increasing size of the older market is inevitable.

The social role of persons 65 years of age and older is in the process of change. With that change and a change in social attitudes of the total population, older persons may feel free to enjoy more of the products of our civilization. With continued advances in the field of geriatrics, older persons may not feel the impact of chronological aging so intensely as did their predecessors. Modern medicine often can cure illness and, if not, medical plans in the form of insurance may relieve major financial concern. When people are well, they have more interest in living, and if they believe they will have many years ahead of them, they will live more actively.

The disposable income of the older population may have been underestimated. With a high rate of mortgage-free home ownership and reduced family size, older persons do not have the same financial obligations as younger people. Although the negative effect of inflation must be considered in any analysis of older persons' financial conditions, the sources of income may counterbalance increased living costs. Retirement plans, income in kind, understatement of assets, favorable tax exemptions, and governmental plans and aids may indicate a heretofore unrecognized disposable income availability.

The market is a difficult one to differentiate. Older persons-if not very oldtend to follow their usual behavior patterns so long as they are able to do so. As 
age progresses the differentiation becomes clearer. Seldom do persons 65 years of age and older want to be differentiated. This increases the difficulty which marketers may encounter when they try to appeal to the older market. Marketers must be aware of this dislike by members of the older market to be categorized as "old." But integrity of a store, quality of merchandise and service, a wide selection of services and products, and consideration for individual desires will attract the older consumer.

As older persons search for satisfying activities, they may make their wants known. If shopping is made pleasant, interesting, and satisfying for the older consumer, more will shop. The marketers must recognize the dual nature of the market in that demand for some products is indirect as older persons purchase gifts and products for their relatives and friends and at the same time receive many of their products as gifts.

Older persons provide a stable market as their income, although lower, tends to be constant. They like to stay in their home town or city. They prefer to shop in the same places and to be served by familiar people who show an interest in their problems. They are concerned with quality and integrity. They want to buy from people whom they can trust.

It is not surprising that marketers are confused concerning the characteristics of the older market. Older persons themselves have few precedents to follow. They are not certain just what is expected of them and may have difficulties in adjusting to their new situations. The educational responsibility for the marketer is clear. The older consumer may be assisted to see his own role as an active participant in modern society who just happens to be 65 years of chronological age or older. 